\title{
MELASMA LIKE PIGMENTATION OVER FACE AFTER CHIKUNGUNYA FEVER - A CASE REPORT
}

V. Shanmugasundaram ${ }^{1}$.

1. Assistant Professor, Department of Dermatology, Karuna Medical College and Hospital Chittur, Palakad, Kerala

\section{CORRESPONDING AUTHOR}

Dr. V. Shanmugasundaram, 411, G.V. Residency,

Sowripalayam, Coimbatore- 641 028. Tamil Nadu.

Email-shanmugammd@yahoo.com

\section{HOW TO CITE THIS ARTICLE:}

V. Shanmugasundaram. "Melasma like Pigmentation Over Face after Chikungunya Fever - A Case Report". Journal of Evolution of Medical and Dental Sciences 2013; Vol2, Issue 26, July 1; Page: 4813-4815.

ABSTRACT: Chikungunya fever is an Arboviral acute febrile illness transmitted by the bite of infected Aedes mosquitoes. CF is characterized by an acute onset of high fever associated with severe disabling arthritis, vomiting, sore throat and often with prominent cutaneous manifestation. The disease is usually self limiting, but the joint symptoms and some cutaneous features may persist after defervescence. Various cutaneous changes have been described in association with CF. Here we are reporting a case of melasma like pigmentation over face observed after chikungunya fever. KEYWORDS: viral fever, pigmentation, melasma,

INTRODUCTION: Chikungunya fever is an acute viral infection caused by Arbovirus, Transmitted by bite of infected aedes mosquitoes. It was documented for the first time after an outbreak in Tanzania 1952(1,2). Explosive outbreaks of epidemics of the disease have occurred after periods of long quiescence in different parts of world. CF has been reported from almost 40 countries (3). The first reported outbreak of CF in India was from Calcutta in 1963. A small outbreak was later reported from Sholapur district in Maharashtra in1973. After a period of quiescence there was a re emergence of CF epidemics in some islands of Indian ocean and south India during 2005 .In the south India outbreak of epidemic in Kerala was observed during the year 2006\&2009(4). Since then cases have been reported from various parts of country. Wide variety of skin and mucous membrane manifestation have been reported in association with Chikungunya Fever(5,6,7,8). Here we report a patient with melasma like pigmentation over face following chikungunya fever.

CASE REPORT: A 45 year old male presented with compliant of pigmented lesion over face for 1 week duration. His history indicates chikungunya fever 2weeks before, 5 days after the CF patient noticed multiple tiny dark spots over cheek and tip of nose. The dark spots had coalesced to form pigmented macule.

On examination dark brown pigmented and well defined macule measuring $1 \times 1 \mathrm{~cm}$ over both cheek and tip of nose was found (fig). No skin lesion over the body during fever. No similar 


\section{CASE REPORT}

pigmented lesions on other parts of body. The patient had not experienced similar compliant earlier. His blood investigation was normal and Chikungunya IgM was positive.

DISCUSSION: Melasma is a symmetrical hyperpigmented macule commonly occurring over cheek, upper lip, chin, nose and forehead. Occasionally it can occur in other sun exposed areas. It may be confluent or punctuate. The patterns of distribution are centro-facial, malar or mandibular. The exact pathogenesis is not known. It may be genetic, ultraviolet rays or hormonal. The treatment is for cosmetic purpose, treatment options are topical or surgical. Chikungunya fever is a re-emerging, self limiting, arboviral infection. The reason for re-emerging of CF in Indian subcontinent is unclear, globalization of trades, increased international travel, abundance of potential vectors like aedes mosquitoes, poor vector control, absence of herd immunity and viral mutations may be the contributing factor(5). CF may affect people of all age group with equal gender distribution after an incubation period of 3-12 days. Characterized by sudden onset of high fever with swollen, tender joint involvement, mostly small joints and can affect large joints, headache, vomiting, sore throat, conjunctivitis and cutaneous lesions. Different types of skin lesions are been reported in chikungunya fever. The most common cutaneous lesion described is erythematous maculopapular rash. Usually skin lesions appear 4-5day after recovering from illness, but may appear simultaneously with fever or after defervescence (5). The rash is asymptomatic in $80 \%$ of the patients, and the remainder may complain of mild pruritus.

The first site of appearance of skin lesions are most frequently the extremities followed by trunk, neck, and ear lobes. Facial involvement is up to $70 \%$ of the cases have been documented (5). A wide variety of skin and mucous membrane manifestation also have been reported. 40-50\% of patients may have cutaneous lesions $(9,10)$. The skin lesion are morbilliform eruption, hypermelanosis, urticarial lesion, xerosis, excoriated papules, desquamation over palms, macular erythema, aphthous like ulcer, genital ulcer, vasculitic ulcer and melasma like lesion over face, macular and pinpoint (confetti) macule, periorbital melanosis, irregular and flagellate pigmentation over trunk, extremities and abdomen(6). Exacerbation of existing dermatosis such as lichen planus, psoriasis and etc has been documented in CF (6). Histopathology of the pigmented lesion may show increased basal pigmentation, pigmentary incontinence and melanophages $(11,12)$. The pathogenesis for pigmentation is not clear, and it could be post inflammatory pigmentation or an increased intra epidermal melanin dispersions/ retention triggered by the virus (6). Basically it is a self limiting illness and do not require any specific anti-viral drugs. Skin lesions are managed symptomatically with antihistamines, emollients, topical steroids. Melanosis managed with reassurance, topical hypo pigmenting agents like hydroquinone with or without topical steroids.

\section{REFERENCE:}

1. Robinson MC. An epidemic of virus disease in southern province, Tanganyika Territory, in 1952-53 Clinical features. Trans R Soc Trop Med Hyg.1955; 49:28 -32.

2. Lumsden WH. An epidemic of virus disease in Southern Province, Tanganyika Territory, in 1952-53; II. General description and epidemiology. Trans R Soc Trop Med Hyg.1955; 49:3357. 
3. World Health Organization, Regional Office for South- East Asia. Guidelines on Clinical Management of Chikungunya Fever. New Delhi: World Health Organization, Regional Office for South -East Asia; 2008.

4. Kannan M, Rajendran R, Sunish TP, Balasubramaniam R, Arunachalam N, Paramasivam R, et al. A Study on Chikungunya outbreak during 2007 in Kerala South India. Indian J Med Res2009; 129:311-15.

5. Bandyopadhyay D, Ghosh SK. Mucocutaneous feature of chikungunya fever: a study from an outbreak in west Bengal, India. Int J Dermatol.2008; 47:1148-52.

6. Inamadar AC, Palit A, Sampagavi VV, Ranganath S, Deshmukh NS. Cutaneous manifestation of chikungunya fever: observation made during a recent outbreak in south India. Int J Dermatol. 2008; 47:154-9.

7. Mishra K, Rajawat V. Chikungunya - induced genital ulcers. Indian J Dermatol Venereol Leprol. 2008; 74:383-4.

8. Prasant S, Kumar AS, Mohammed Basheeruddin DD, Chowdhary TN, Madhu B. Cutaneous manifestations in patients suspected of chikungunya disease. Indian J Dermatol. 2009; 54:128-31.

9. Staikowsky F, Talarmin F, Grivard P, Souab A, Schuffenecker I, Le Roux K, et al. Prospective study of chikungunya virus acute infection in the Island of La Reunion during the 2005-2006 outbreak. PLoS One.2009; 28:4.

10. Simon F, Parola P, Grandadam M, Fourcade S, Oliver M, Brouqui P, et al. Chikungunya infection: an emerging rheumatism among travellers returned from Indian ocean islands. Report of 47 cases. Medicine (Baltimore) 2007; 86:123-37.

11. Shivakumar V, Rajendra O, Rajkumar V, Rajasekhar TV. Unusual facial melanosis in viral fever. Indian J Dermatol 2007; 52: 116-17.

12. Swaroop A, Jain A, Kumhar M, Parihar N, Jain S. Chikungunya fever. J Indian Acad Clin Med 2007; 8: 164-68.

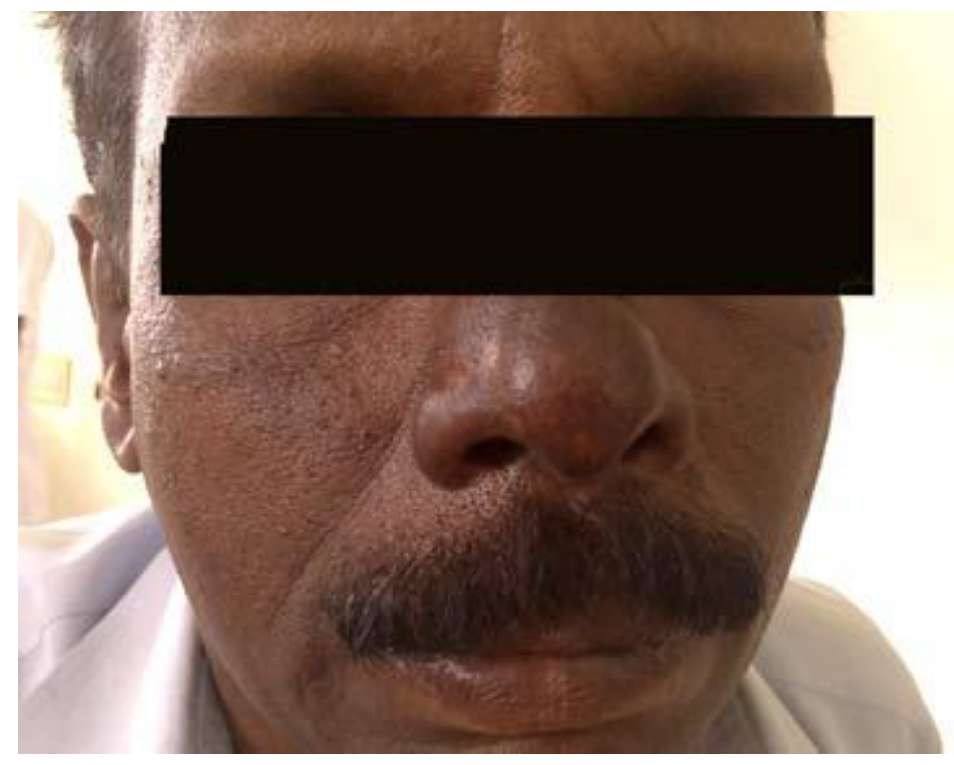

